Doi: $\underline{\text { dx.doi.org/10.17921/2525-5320.2016.310-315 }}$

\title{
FORMULAÇÃO DE UM IDEAL COMUNITÁRIO E SUA APLICAÇÃO EM UM CENTRO DE EDUCAÇÃO PROFISSIONAL PARA A SAÚDE
}

\author{
Flávia Luísa Dias* - Mater Ter Admirabilis \\ Cilene Teixeira Guimarães* - Mater Ter Admirabilis \\ Maria Piassa Lourenço Bernardino* - Mater Ter Admirabilis
}

Palavras-chave: Pedagogia de Schoenstatt. Ideal Comunitário. Educação Profissional

\section{INTRODUÇÃO}

Em 1996, Jacques Delors e outros membros da Comissão Internacional sobre educação para o Século XXI redigiram um relatório à UNESCO problematizando as principais tensões deste século e recomendando formas de superá-las a partir da educação. Um dos problemas citados é a tensão entre o universal e o singular. A globalização da cultura é algo progressivo e promete avanços, porém o esquecimento do caráter, único de cada indivíduo, sua vocação e sua liberdade para decidir seu próprio destino, realizando todas as suas potencialidades e conservando a riqueza de suas tradições, torna-se um grande risco sob a influência deste conceito de "senso cultural comum" (DELORS, 1996).

De acordo com o relatório, o ser humano nem sempre tem a capacidade e sensibilidade de vislumbrar e exprimir seu estado anímico e, por isso, tem sede de um ideal ou de valores. Faz-se necessário, para a sobrevivência da humanidade, suscitar valores morais e ideais elevados, gerando uma sociedade que busca a superação de si mesma, o encontro com o universal, a solidariedade e o respeito pelo pluralismo (DELORS, 1996).

Segundo Teodoro (2010), a procura de uma alternativa ao plano ideológico para a educação diante dos dilemas atuais, aponta como questão central: é

\footnotetext{
${ }^{\star}$ E-mail: flavia.luisa@iscal.com.br *E-mail: cileneguimaraes@outlook.com.br *E-mail: ma_Ibernardino@hotmail.com
} 
possível, nos tempos de hoje, construir as bases de um novo senso comum, capaz de ajudar a formular uma agenda educativa e um novo bloco social interessado em impulsionar (e realizar) a paz, a justiça social, a felicidade e a liberdade? O autor ressalta:

A sociedade contemporânea demanda também uma educação contemporânea, que atenda às exigências de um mundo globalizado e de um homem tecnologizado, mas que não pode ser incompatível ao princípio primeiro da educação, o processo humanizador (TEODORO, 2010, p.76).

A educação tem como tarefa gerar nos educandos, dentro de suas próprias tradições e convicções, essa elevação de pensamento e de espírito. De fato, sua função de construir profissionais, tornando-os qualificados e capazes de atender às demandas da sociedade não é menos importante que a de formar pessoas comprometidas com a relevância e a qualidade do seu trabalho e capazes de refletir sobre sua própria missão no mundo (COTTA et al, 2007).

Neste contexto, a Pedagogia sustentada pela Obra Internacional de Schoenstatt, fundada pelo Padre José Kentenich em 1914 na Alemanha, vai ao encontro das preocupações atuais e norteia princípios educativos a fim de formar personalidades autênticas que atuam com liberdade como protagonistas de uma nova ordem social.

Padre Kentenich toma os princípios filosóficos tomista: "ordem do ser é a ordem do agir" e "a graça pressupõe a natureza; a graça não destrói, mas aperfeiçoa e eleva a natureza" e o princípio salesiano: "o amor é a lei fundamental do um mundo", como fundamentação do seu sistema de educação (KENTENICH, 1997).

Na Pedagogia de Schoenstatt, cada educando é a concretização de uma ideia original de Deus. Cabe aos educadores ajudá-lo na sua autoeducação, conduzindoo a descobrir e a concretizar, realmente, o ideal que Deus teve dele ao criá-lo. Este amor respeitoso do educador desperta no educando todas as capacidades e o impulso em buscar, no cotidiano de sua vida, as características desta ideia original. Ser aquilo que ele é e para aquilo que ele foi criado, proporciona ao educando alegria e dá sentido à sua vida (CENTRO DE EDUCAÇÃO PROFISSIONAL MATER TER ADMIRABILIS, 2015). 
A conquista e aplicação de um ideal fundado em motivos sólidos são inspiradas, em Schoenstatt, nos valores cristãos e conduzidos pela Mãe de Deus, por meios de instrumentos pedagógicos. Cada novo conhecimento e prática educativa são dispostos da força e Graça recebida do sobrenatural, sendo necessário compreender que Maria auxilia em nossas conquistas, por ser Auxiliar e Consorte permanente do grande Educador, Jesus Cristo (KENTENICH, 1984)

Neste contexto, este trabalho tem como objetivo descrever um relato de experiência do Centro de Educação Profissional Mater Ter Admirabilis (CEPMTA) sobre a formulação do ideal da instituição e sua aplicação na formação pessoal e profissional dos docentes e estudantes de cursos técnicos na área da saúde.

O Centro de Educação Profissional Mater Ter Admirabilis é um departamento da Irmandade da Santa Casa de Londrina (ISCAL), entidade filantrópica, e teve o início de suas atividades em $1^{\circ}$ abril de 1960. O alicerce educacional da escola foi o Sistema Pedagógico de Schoenstatt, que permitiu que essa se tornasse, para Londrina e norte do Paraná, uma Instituição Educacional voltada à formação do ser humano integral, promovendo o desenvolvimento intelectual, biopsicossocial, religioso, afetivo e ético da pessoa humana.

O Padre José Kentenich, fundador desta Pedagogia, distingue as estrelas condutoras para que a tarefa grandiosa de formar personalidades autênticas e livres seja exercida, relacionando o ambiente, o sujeito, o objeto, o fim e o processo da educação. Dentre elas, está a Pedagogia do Ideal, que atua formando atitudes e não apenas atos e exercícios. Segundo Padre Kentenich (1984), o ideal comunitário "como estrela luminosa, está anteposta à comunidade e por ele se orientam todas as manifestações de vida", tendo como valor principal a criação da atitude da qual a pessoa forma e domina sua vida por ação própria e autônoma.

A partir destes preceitos, o CEPMTA, desde a sua fundação, tem como parte de sua grade curricular, a formação pessoal do educando na disciplina de Pastoral da Saúde. Nesta, o estudante é envolvido por temas de espiritualidade e motivado a buscar o autoconhecimento, a autoeducação e a entender seu propósito no mundo.

Em 1963, surge o primeiro ideal de consagração de turma: "Praesto Serviendi in Caritate", do latim, "Pronto para servir no amor". Este ideal tem como cerne a prontidão, o serviço e a caridade, características fundamentais para que os 
profissionais em formação pudessem atuar de forma autêntica no cuidado à saúde.

É possível considerar que um ideal tão nobre só poderia surgir de educandos que compreenderam a proposta pedagógica de Schoenstatt e assumiram a missão de serem, no trabalho e nos outros âmbitos da vida, personalidades firmes, livres e autênticas.

Desde então, diversas turmas conquistaram seus ideais comunitários, todos centrados no amor e na doação. Até o ano de 2005 cada turma, que tinha em média de 20 a 30 alunos, formulava seu próprio ideal. Alguns como "Seja minha vida um constante enriquecer, para que se torne um perene doar", "Doar-se, um gesto de amor" e "Ser luz para servir" foram assumidos por mais de uma turma, demonstrando a consonância na forma de educar e orientar dos docentes e no entendimento da pedagogia pelos educandos.

Com a expansão do CEPMTA e consequente aumento do número de alunos, e apoiadas na visão de que todos os ideais até então conquistados, mesmo que com formulações diferentes, expressavam os mesmos anseios, as lideranças do centro educacional decidiram formular um único ideal comunitário para a Instituição. Juntamente com o corpo docente e discente, por meio da lluminação Divina e de intensas contribuições ao Capital de Graças, elaboraram um ideal que revelava a harmonia vivida pela escola e que deveria perdurar, transmitido por seus criadores, como herança para as próximas turmas que se formassem.

Por isso, o CEPMTA, antiga Escola de Auxiliares de Enfermagem, carrega desde 2005 em seus princípios filosóficos e educacionais o ideal comunitário "Sê uma Luz que ilumina, aquece e vivifica". Este, que é uma ramificação do ideal da ISCAL de ser "Reino da Luz", relembra o símbolo da Enfermagem Moderna, a lâmpada que guiava os passos de Florence Nightingale em meados de 1850 no cuidado aos feridos da guerra da Criméia. O efeito da luz, que possibilitava o atendimento aos soldados, também diminuía a solidão e a dor daqueles, animandoos para lutar pela vida (COSTA et al., 2009).

O ideal, mesmo trazendo traços da história da Enfermagem, não se restringe aos docentes e educandos deste curso técnico. Atualmente, o CEPMTA oferece outros três cursos técnicos na área da saúde (Radiologia, Análises Clínicas e 
Podologia), e estes se sentem tão inspirados pelo ideal quantos os que seguem os caminhos da lâmpada de Florence.

A formulação é feita no imperativo, que acentua o caráter de apropriação apostólica e impulsiona, para que este não fique somente nas palavras e ações superficiais. O ideal "Sê uma luz" deve encorajar os estudantes e futuros profissionais de saúde inspirados pelos exemplos de seus educadores, a iluminar o ambiente esmorecido pela dor, aquecer os corações sofredores e os vivifique na esperança do perfeito restabelecimento.

Depois de mais de 10 anos de sua conquista e elaboração, o ideal ainda arde nos corações dos estudantes que permitem vivenciá-lo. Todas as turmas, no segundo módulo de seus cursos recebem a formação sobre a história do ideal e são orientados em como podem assumi-lo, sendo convidados a uma Consagração a Jesus e Maria e também ao ideal de ser luz que ilumina, aquece e vivifica.

As notáveis consequências desta ideia ousada são vistas tanto pelos novos funcionários e docentes que ingressam em um ambiente de trabalho acolhedor e empático quanto pelos alunos que se sentem livres para construir sua formação profissional, sem sentirem-se subordinados e apenas receptores de informação como no sistema tradicional de educação.

Além disto, o ideal suscitado aos educandos proporciona ao egresso uma formação crítico-reflexiva no planejamento de suas ações, principalmente na tomada de iniciativa, de compromisso técnico, de equilíbrio emocional e de decisões na comunicação interpessoal, formando um profissional ativo, reflexivo na proposição de transformações, capaz de atuar em nosso contexto sócio, político e econômico com desenvolvimento das competências técnica, política e ética.

Segundo Santos e Incontri (2010), somente por um processo educacional amplo, plural e interdisciplinar envolvendo a educação, a saúde e a espiritualidade, poderemos conciliar o lado material e espiritual do ser humano e avançar em uma proposta de cuidar e de curar. Neste sentido, o ideal de ser luz fomentado nos educandos do CEPMTA permite que estes se sintam empoderados de autonomia e estimulados a construir vínculos significativos em suas relações com o paciente necessitado de cuidado e afeto. 
Com este relato é possível vislumbrar a Pedagogia do Ideal da Obra Internacional de Schoenstatt nos modelos educacionais de formação profissionalizante na área da saúde e, se possível, contribuir para a divulgação dos efeitos positivos da aplicação deste sistema educacional, visionado por Padre Kentenich em 1914, que até hoje gera frutos e colabora no desenvolvimento pessoal e profissional dos formadores, educadores e educandos.

\section{REFERÊNCIAS}

CENTRO DE EDUCAÇÃO PROFISSIONAL MATER TER ADMIRABILIS, Projeto Político Pedagógico. Irmandade Santa Casa de Londrina - Educação Profissional Técnica na Área da Saúde. Londrina - PR, 2015

COSTA, R. et al. O legado de Florence Nightingale: uma viagem no tempo. Texto Contexto Enferm., v.18, n.4, p.661, 2009.

COTTA, R.M.M. et al. Pobreza, injustiça, e desigualdade social: repensando a formação de profissionais de saúde. Rev. Bras. Educ. Méd., v.31, n.3, p.278-286, 2007.

DELORS, J. et al. Educação: um tesouro a descobrir - Relatório para a UNESCO da Comissão Internacional sobre Educação para o Séc. XXI. 1996.

KENTENICH, J. Linhas fundamentais de uma pedagogia moderna para o educador católico. Santa Maria: Palloti, 1984.

KENTENICH, J. Minha filosofia de educação. Santa Maria-RS, 1997.

SANTOS, F.S.; INCONTRI, D. A arte de cuidar-saúde, espiritualidade e educação. São Paulo: Comenius, 2010.

TEODORO, A. Educação, globalização e neoliberalismo: os novos modos de regulação transnacional das políticas de educação. Porto: Edições Universitárias Lusófonas, 2010. 